\title{
Qualidade de Carcaças de Cordeiros Corriedale, Bergamácia x Corriedale e Hampshire Down x Corriedale, Terminados em Pastagem e Confinamento ${ }^{1}$
}

\author{
Francisco de Assis Fonseca de Macedo², Edson Ramos de Siqueira ${ }^{3}$, Elias Nunes Martins², \\ Rosa Maria Gomes de Macedo ${ }^{4}$
}

\begin{abstract}
RESUMO - O objetivo deste experimento foi comparar as características qualitativas de carcaças de 36 cordeiros terminados em pastagem de coastcross, sendo 13 Corriedale, 14 Bergamácia x Corriedale e 9 Hampshire Down x Corriedale, e 29 cordeiros terminados em confinamento, sendo 10 Corriedale, 11 Bergamácia x Corriedale e 8 Hampshire Down x Corriedale. As médias das variáveis (escala de 1 a 5) condição corporal: 2,70 e 3,13; conformação: 2,65 e 3,35; e cobertura de gordura: 2,43 e 2,95; foram superiores para os cordeiros do confinamento que para cordeiros em pastagem. Na escala de 1 a 3, foram avaliadas a cor da gordura: 1,66 e 1,94; cor da carne: 1,66 e 1,72; e consistência de gordura: 1,62 e 1,83, respectivamente, para os cordeiros em pastagem e em confinamento. A área de olho de lombo foi significativamente $\left(10,21\right.$ vs. $\left.9,03 \mathrm{~cm}^{2}\right)$, bem como a espessura de gordura de cobertura: $1,10 \mathrm{vs} .1,70 \mathrm{~mm}$, foi superior para os cordeiros confinados. As médias das porcentagens de músculo no lombo foram de 54,92 e 57,94\%; para gordura, 9,29 e 12,95\%; e osso, 35,78 e 29,10\%, respectivamente, para cordeiros em pastagem e confinamento. Entre os sistemas de terminação, não houve diferenças para porcentagem de proteína (19,71 e 19,10\%, respectivamente), mas houve diferença para teor de lipídios, com 5,43\% para cordeiros em pastejo e 11,54\% para cordeiros confinados. Para as variáveis analisadas não houve diferenças significativas entre os cruzamentos.
\end{abstract}

Palavras-chave: carne ovina, ovinos, produção de carne, sistemas de terminação

\section{Carcass Quality of Corriedale, Bergamacia x Corriedale, and Hampshire Down $x$ Corriedale Lambs, Finished on Pasture or Dry-Lot}

\begin{abstract}
The objective of this experiment was to compare qualitative carcass characteristics of 36 lambs that were finished in coastcross pasture, being 13 Corriedale, 14 Bergamacia x Corriedale, and 9 Hampshire Down x Corriedale, and 29 lambs tha twere finished in a dry-lot system, being 10 Corriedale, 11 Bergamacia x Corriedale, and 8 Hampshire Down x Corriedale. The average of the variables (scale ranging from 1 to 5), body condition score (2.70 vs 3.13.), conformation (2.65 vs. 3.35) and subcutaneous fat (2.43 vs. 2.95.) were higher for dry-lot lambs than for grazing lambs. On a scale ranging from 1 to 3 , the fat color average of 1.66 and 1.94 , meat color 1.66 and 1.72, and fat consistency: 1.62 and 1.83, respectively, for pasture lambs and for dry-lot lambs were evaluated. The longissimus muscle area $\left(10.21 \mathrm{~cm}^{2} \mathrm{vs} .9 .03 \mathrm{~cm}^{2}\right)$, as well as for fat thickness $\left(1.70 \mathrm{~mm}^{2} \mathrm{vs} .1 .10 \mathrm{~mm}^{2}\right.$, was significantly higher for drylot lambs. The average for the percentage of muscle in the Longissimus muscle were 54.92 and 57.94\%; for fat, 9.29 and $12.95 \%$; and bone, 35.78 and $29.10 \%$, respectively, for grazing lambs and dry-lot lambs. The finishing system did not affect the percentage of protein ( 19.71 and $19.10 \%$, respectively), but it affected fat content, $5.43 \%$ for grazing lamb and $11.54 \%$ for dry-lot lamb. Cross breeding did not significantly affect the studied variables.
\end{abstract}

Key Words: finishing systems, meat production, sheep, sheep meat

\section{Introdução}

O aumento da produção de carne ovina, para atendimento da demanda potencial, deverá estar acompanhado por técnicas que propiciem a apresentação de carcaças de alta qualidade. A condição corporal é uma avaliação subjetiva realizada nos ovinos vivos, que indica a proporção entre as massas muscular e adiposa, em relação ao osso (JARRIGE, 1988), orien- tando a melhor época de abate, com a finalidade de se obter carcaças com bom acabamento. OSÓRIO et al. (1995), avaliando condição corporal em cordeiros Corriedale, terminados em pastagem nativa do Rio Grande do Sul, abatidos com peso médio de $29,80 \mathrm{~kg}$, encontraram média de 3,17 pontos (escala de 1 a 5). FERNANDES (1994) encontrou diferenças para condição corporal entre cordeiros Corriedale $(2,51) \mathrm{e}$ Ile-de-France x Corriedale $(2,74)$, terminados em

\footnotetext{
1 Parte da Tese apresentada à UNESP - Botucatu pelo primeiro autor, para obtenção do título de Doutor.

2 Professor do Departamento de Zootecnia, Centro de Ciências Agrárias, Universidade Estadual de Maringá, Av. Colombo 5.790, 87.020-900, Fone (44)261-4319, Maringá - PR. E.mail: fafmacedo@uem.br

3 Professor do Departamento de Produção Animal, Fac. Med. Veterinária e Zootecnia, UNESP, Botucatu.

4 Professor do Departamento de Morfofisiologia da Universidade Estadual de Maringá, doutoranda do curso de Zoologia - IB - UNESP, Botucatu.
} 
confinamento, abatidos entre 30 e $32 \mathrm{~kg}$ de peso vivo na origem.

Carcaças bem conformadas causam melhor impressão aos consumidores. FARIAS (1986) afirmou que a conformação permite avaliar, principalmente, o desenvolvimento muscular da carcaça. Segundo SAÑUDO e SIERRA (1986) as carcaças bem conformadas são as que apresentam morfologia compacta, curta e larga, pernas globosas e planos musculares desenvolvidos, com predominância de perfis convexos, em todas as regiões corporais. Por outro lado, os autores salientaram que, em vários estudos comparando carcaças de ovinos e bovinos com conformação boa e ruim, as bem conformadas apresentaram maiores teores de gordura. A maioria dos países envolvidos na comercialização de carcaças de ovinos tem adotado a conformação como critério de avaliação, valorizando-se mais as carcaças de conformação superior. LIRETTE et al. (1984), trabalhando com cordeiros Suffolk e Finish-Landrace, e FERNANDES (1994), com Corriedale e mestiço Ilede-France x Corriedale, observaram efeito de genótipo sobre a conformação. Deve-se considerar que nestes dois trabalhos os grupos genéticos eram de diferentes aptidões, o que provavelmente, explica os resultados discordantes dos encontrados por SAÑUDO et al. (1992) que trabalharam com grupos genéticos de mesma aptidão, as raças leiteiras Aragonesa e Lacaune, e WYLIE et al. (1997), que trabalharam com as raças de corte Suffolk e Texel.

No momento da compra de carne, grande parte dos consumidores observa primeiramente a sua cor. JONES et al. (1984) não encontraram diferenças para cor da carne de cordeiros terminados em pastagem ou confinamento.

A área de olho de lombo é uma medida objetiva, de grande valor na predição da quantidade de músculo da carcaça. Comparando o efeito do sistema de terminação (pastagem e confinamento) sobre a área de olho de lombo, McCLURE et al. (1994) detectaram diferenças, contrariando resultados encontrados por ARNOLD e MEYER (1988). O efeito de genótipo para esta variável foi observado por vários pesquisadores, destacando: WOLLF et al. (1980), DAHMEN et al. (1985), ARNOLD e MEYER (1988) e FAHMY et al. (1992), em contraposição aos resultados encontrados por CROUSE et al. (1981), LLOYD et al. (1981), SNOWDER et al. (1994) e WYLIE et al. (1997).

O teor de tecido adiposo na carcaça ovina é fator determinante de sua qualidade. Sua mensuração pode ser objetiva ou subjetiva. A avaliação subjetiva leva em consideração a gordura de cobertura. LATIF e OWEN (1980) e FERNANDES (1994), trabalhando com cordeiros confinados, não detectaram efeito de genótipo para cobertura de gordura (médias de 2,94 para peso de abate de $36,3 \mathrm{~kg}$ e 2,55 pontos para abate realizado com 30,0 a $32,0 \mathrm{~kg}$, respectivamente). Já OSÓRIO et al. (1995) obtiveram grau de gordura de 3,5 para carcaças de cordeiros Corriedale sacrificados com 29,58 $\mathrm{kg}$ de peso vivo, terminados em pastagem nativa no Rio Grande do Sul. Provavelmente, essa superioridade na cobertura de gordura decorreu do maior tempo que os animais levaram, em pastagem nativa, para atingirem peso de abate.

A gordura é o componente da carcaça que apresenta maior variação, influenciada principalmente pelo sistema de terminação, pelo genótipo e pela razão idade/peso do animal. É uma questão de fundamental importância, haja vista a aversão do consumidor moderno pelo excesso de tecido adiposo.

Efeito de genótipo sobre a cobertura de gordura foi verificado por ARNOLD e MEYER (1988) e FAHMY et al. (1992), contrariando resultados de CROUSE et al. (1981), ELLIS et al. (1997) e WYLIE et al. (1997).

A dissecção completa da carcaça é o método mais exato para avaliação de sua composição tecidual, mas, por ser lento e oneroso, tem-se usado parte representativa da carcaça (OSÓRIO, 1992).

Segundo GALVÃO et al. (1991) e OSÓRIO (1992), os tecidos muscular, adiposo e ósseo são os de maior interesse na comparação de carcaças de ovinos. O osso é o tecido de desenvolvimento mais precoce e o músculo, o mais importante na valorização da carcaça, enquanto o adiposo o que mais interfere na composição tecidual (OSÓRIO, 1992).

JONES et al. (1984) observaram efeito de sistemas de terminação na proporção de músculo:gordura:osso, com superioridade dos cordeiros terminados em confinamento. Efeito de genótipo sobre esta variável foi encontrado por diversos autores (LATIF e OWEN, 1980; WOLF et al.,1980; SAÑUDO et al., 1981; BUTLER-HOGG, 1984; LIRETTE et al., 1984; CAMERON e DRURY,1985; FAHMY et al., 1992; e SAÑUDO et al., 1992). GÚNEY (1988) já não encontrou efeito significativo.

O teor de proteína na carcaça dos animais domésticos diminui com o aumento da idade, enquanto a quantidade de lipídio aumenta. Logo, deve-se procurar abater ovinos jovens, desde que apresentem pesos de carcaça compatíveis com a exigência do consumidor. Testando sistemas de terminação de 
1522 Rev. bras. zootec.

cordeiros, MURPHY et al. (1994) não observaram efeito sobre os níveis de proteína; por outro lado, a porcentagem de lipídio foi superior para os cordeiros terminados em confinamento. SNOWDER et al. (1994) constataram efeito de genótipos para proteína e lipídio e MEYER e KIRTON (1984), somente para lipídio.

Diante do exposto, o objetivo do presente trabalho foi comparar as características qualitativas de carcaças de cordeiros Corriedale e mestiços Bergamácia x Corriedale e Hampshire Down x Corriedale, terminados em pastagem e confinamento.

\section{Material e Métodos}

No Centro de Pesquisa do Arenito, em Cidade Gaúcha, pertencente à Universidade Estadual de Maringá, foram produzidos 65 cordeiros, machos inteiros, filhos de ovelhas Corriedale, sendo 22 puros, filhos de sete carneiros Corriedale (C); 26 cruzados, filhos de oito carneiros Bergamácia (BC) e 17 cruzados, filhos de sete carneiros Hampshire Down (HC). Desde o nascimento, os cordeiros tinham acesso à mistura de sal mineral. Entre o $3 \underline{0}$ e 5ㅇ dia de vida todos, foram caudectomizados; com 15 dias, vacinados contra ectima contagioso; e aos 45 dias, vacinados contra carbúnculo, gangrena gasosa e enterotoxemia. Acompanharam suas mães até os 60 dias de vida, quando então foram desmamados bruscamente, everminados e distribuídos em dois sistemas de terminação. Trinta e seis cordeiros, sendo $13 \mathrm{C}, 14 \mathrm{BC}$ e $9 \mathrm{HC}$, foram terminados em pastagem de coastcross (Cynodon dactylon), que apresentou composição média de $18 \%$ de proteína bruta (PB) e $72 \%$ de nutrientes digestíveis totais (NDT). Outros 29 cordeiros foram terminados em confinamento, sendo $10 \mathrm{C}$, $11 \mathrm{BC}$ e $8 \mathrm{HC}$.

No confinamento, os animais receberam uma ração completa, à vontade com os mesmos teores de PB e NDT da pastagem, constituída dos seguintes ingredientes: $41,5 \%$ de milho desintegrado com palha e sabugo; $22,75 \%$ de milho grão, moído em peneira grossa; $19 \%$ de farelo de soja; $15 \%$ de farelo de trigo; $0,75 \%$ de fosfato bicálcico, e 1,0\% de calcário.

No início do experimento, os cordeiros apresentaram peso vivo médio de $9,6 \mathrm{~kg}$. Ao atingirem a faixa de 30 a $32 \mathrm{~kg}$ de peso vivo, na origem, eram colocados exclusivamente sob dieta hídrica durante 18 horas, quando eram novamente pesados (peso vivo ao abate) para procedimentos de abate. Previamente ao sacrifício, determinou-se a condição corporal (CC) palpação da região lombar, conferindo-se nota de 1,00 a 5,00 (1,00 para pior e 5,00 para a melhor).

Após 24 horas em geladeira frigorífica, com temperatura entre 0 e $4^{\circ} \mathrm{C}$, as carcaças foram avaliadas visualmente, segundo metodologia citada por COLOMER-ROCHER (1988), como segue:

-grau de conformação(CC), considerando a carcaça como um todo, dando ênfase às diferentes regiões anatômicas: perna, garupa, lombo e escápula, bem como à espessura de seus planos musculares e adiposos, em relação ao esqueleto que a suporta, atribuindo-se 1,00 para muito pobre e 5,00, para excelente;

-cobertura de gordura (CBG), sendo 1,00 para excessivamente magra e 5,00 para excessivamente gorda.

Para cor da gordura, consistência da gordura e cor da carne, utilizou-se a escala de 1,00 a 3,00 pontos;

-cor da gordura (CG), 1,00 para branca e 3,00 amarela;

-consistência da gordura (CSG), 1,00 para firme e 3,00 mole;

-cor da carne (CCA),1,00 para rosa e 3,00 roxa.

Todas as notas referentes à avaliação subjetiva foram fracionadas em 0,25 .

Os lombos foram separados individualmente e dissecados no laboratório do Centro de Pesquisa do Arenito, da Universidade Estadual de Maringá, para determinação proporcional de músculo $(\mathrm{M})$, gordura (G) e osso (O).

No lombo, tomou-se a área transversal em transparência e, posteriormente, por intermédio do programa computacional AUTOCAD, foi determinada a área de olho de lombo. Ainda no lombo, utilizando-se paquímetro, foi medida a espessura de gordura de cobertura sobre a secção do mesmo (entre a última vértebra torácica e primeira lombar).

No Laboratório do Departamento de Química, da Universidade Estadual de Maringá, foram determinados os teores de proteína total, conforme SILVA (1990), e lipídio, segundo FOLCH et al.(1957), para as amostras retiradas dos lombos.

Análise dos dados

Os dados obtidos foram analisados pelo método de quadrados mínimos empregando-se um modelo que pressupunha efeitos de sistemas de terminação, pastagem ou confinamento, de grupos genéticos C, $\mathrm{BC}$ e HC, bem como da interação entre sistemas de terminação e grupos genéticos. 


\section{Resultados e Discussão}

Médias e desvios-padrão estimados para condição corporal, conformação, cobertura de gordura, cor da gordura, cor da carne e consistência da gordura, de acordo com o sistema de terminação e o genótipo, são mostrados na Tabela 1 .

Não houve efeito significativo $(\mathrm{P}>0,05)$ para interação sistemas de terminação e grupos genéticos, sobre qualquer característica analisada.

A condição corporal dos cordeiros confinados (media de 3,13) foi superior $(\mathrm{P}<0,05)$ à dos mantidos em pastagem $(2,70)$. A avaliação da quantidade de gordura na carcaça confirmou os resultados obtidos para condição corporal, pois os cordeiros terminados em confinamento apresentaram maior quantidade de gordura subcutânea. Tal constatação está de acordo com CAÑEQUE et al. (1989), que citaram alta correlação $(0,97)$ entre o total de gordura da carcaça e da região usada para determinação da condição corporal.

Os cordeiros confinados apresentaram melhor conformação de carcaça (média de 3,35 ) que os terminados em pastagem $(2,65)(\mathrm{P}<0,05)$, o que também pode estar associado aos níveis superiores de gordura na carcaça dos primeiros. Segundo SAÑUDO e SIERRA (1986), conformação avantajada pode estar atrelada a maiores teores de gordura. Tanto técnicos como criadores atribuem enorme

importância à conformação, considerando-a como fator importante para estimar a quantidade e a qualidade da carne existente em um animal, visto que da morfologia in vivo do animal dependerá o rendimento de sua carcaça (OSÓRIO, 1992). Carcaças bem conformadas causam melhor impressão aos consumidores. A maioria dos países envolvidos na comercialização de carcaças de ovinos tem adotado a conformação como critério de avaliação, valorizando-se mais as carcaças de conformação superior.

Os cordeiros terminados em pastagem tiveram menor valor para cobertura de gordura em suas carcaças (média de 2,43) comparados aos terminados em confinamento $(2,95)(\mathrm{P}<0,05)$, corroborando os resultados de ARNOLD e MEYER (1988), MANTEROLA et al. (1991) e McCLURE et al. (1994). É importante lembrar que a gordura interfere no valor comercial da carcaça, pois a avaliação que apresenta maiores variações, podendo ser um fator depreciativo na carcaça dos ovinos, quando em excesso, para os consumidores da maioria dos países, excetuando-se os do Oriente Médio (TEIXEIRA et al., 1992). Entretanto, cobertura mínima de gordura é desejável, para proteção da carcaça, quanto à perda de água, durante a sua conservação, devendo-se também evitar as queimaduras originadas no processo de congelamento.

A gordura apresentou diferenças em sua cor

Tabela 1 - Médias e desvios-padrão para condição corporal (CC), conformação (CO) cobertura de gordura (CBG), cor da gordura (CG), cor da carne (CCA), e consistência da gordura (CSG) de cordeiros, de acordo com o sistema de terminação e o genótipo

Table 1 - Means and standard deviations for body condition (BC), conformation (CO), subcutaneous fat (SF), fat color (FC), meat color (MC) and fat consistency (FCY) of lambs, in function of the finishing system and genotype

\begin{tabular}{|c|c|c|c|c|c|}
\hline \multirow[b]{2}{*}{$\begin{array}{l}\text { Variável } \\
\text { Variable }\end{array}$} & \multicolumn{2}{|c|}{$\begin{array}{l}\text { Sistema de terminação } \\
\text { Finishing system }\end{array}$} & \multicolumn{3}{|c|}{$\begin{array}{l}\text { Genótipo } \\
\text { Genotype }\end{array}$} \\
\hline & $\begin{array}{c}\text { Pastagem } \\
\text { Grazing }\end{array}$ & $\begin{array}{c}\text { Confinamento } \\
\text { Drylot }\end{array}$ & $\mathrm{C}$ & $\mathrm{BC}$ & $\mathrm{HC}$ \\
\hline$\overline{\mathrm{CC}}$ & $2,70 \pm 0,09^{b}$ & $3,13 \pm 0,10^{\mathrm{a}}$ & $2,92 \pm 0,10^{\mathrm{a}}$ & $2,97 \pm 0,09^{\mathrm{a}}$ & $2,86 \pm 0,13^{\mathrm{a}}$ \\
\hline CO & $2,65 \pm 0,08^{b}$ & $3,35 \pm 0,09^{\mathrm{a}}$ & $2,91 \pm 0,09^{\mathrm{a}}$ & $2,95 \pm 0,08^{\mathrm{a}}$ & $3,14 \pm 0,11^{\mathrm{a}}$ \\
\hline $\begin{array}{l}\text { CBG } \\
S F\end{array}$ & $2,43 \pm 0,12^{\mathrm{a}}$ & $2,95 \pm 0,13^{b}$ & $2,59 \pm 0,14^{\mathrm{a}}$ & $2,72 \pm 0,12^{\mathrm{a}}$ & $2,76 \pm 0,17^{\mathrm{a}}$ \\
\hline $\begin{array}{l}\text { CG } \\
F C\end{array}$ & $1,66 \pm 0,07^{\mathrm{a}}$ & $1,94 \pm 0,08^{b}$ & $1,81 \pm 0,09^{\mathrm{a}}$ & $1,78 \pm 0,08^{\mathrm{a}}$ & $1,80 \pm 0,11^{\mathrm{a}}$ \\
\hline $\begin{array}{l}\text { CCA } \\
M C\end{array}$ & $1,66 \pm 0,07^{\mathrm{a}}$ & $1,72 \pm 0,08^{\mathrm{a}}$ & $1,72 \pm 0,08^{\mathrm{a}}$ & $1,71 \pm 0,07^{\mathrm{a}}$ & $1,65 \pm 0,10^{\mathrm{a}}$ \\
\hline $\begin{array}{l}\text { CSG } \\
F C Y\end{array}$ & $1,62 \pm 0,08^{\mathrm{a}}$ & $1,83 \pm 0,09^{\mathrm{a}}$ & $1,66 \pm 0,10^{\mathrm{a}}$ & $1,81 \pm 0,09^{\mathrm{a}}$ & $1,71 \pm 0,12^{\mathrm{a}}$ \\
\hline
\end{tabular}

Médias, na linha, seguidas de letras diferentes diferem $(P<0,05$; Tukey).

Means, within a row, followed by different letters differ $(P<.05$; Tukey).

Corriedale (C); 1 1/2 Bergamácia + 1/2 Corriedale (BC); 1/2 Hampshire Down + 1/2 Corriedale (HC). 
1524 Rev. bras. zootec.

$(\mathrm{P}<0,05)$, com a dos cordeiros da pastagem (média de 1,66) aproximando-se mais do branco, comparada à dos terminados em confinamento $(1,94)$. Ambos os valores, contudo, refletem uma coloração não muito amarela, perfeitamente aceita pela maioria dos consumidores, pois os animais de ambos tratamentos foram abatidos antes dos 10 meses de idade (MACEDO, 1998). Entretanto, esperava-se que acontecesse o contrário, onde a cor da gordura dos animais da pastagem fosse mais para o amarelo, pois esses atingiram peso médio de abate 39 dias depois dos terminados em confinamento.

A cor da carne foi semelhante para os dois sistemas de terminação ( $\mathrm{P}>0,05)$, apresentando-se mais próxima da cor rosa (média 1,69), visto que os animais foram abatidos em idade jovem, corroborando os resultados de JONES et al. (1984). A cor é uma das primeiras características observadas pelos consumidores, e a cor pálida (rosa) na carne de ovinos denota ser originária de animais jovens, além do repouso adequado dos animais para o abate.

Os dois sistemas de terminação mostraram-se semelhantes $(\mathrm{P}>0,05)$, quanto à consistência de gordura. Esperar-se-ia que os animais confinados apresentassem gordura menos consistente, fato que denotaria maiores teores de ácidos graxos insaturados. Segundo LOPEZ-FRANCOS (1991), os ácidos graxos saturados podem variar de $59 \%$, com dietas ricas em forragens, a $38 \%$, nas ricas em concentrados.
Não se constatou efeito de genótipo para as variáveis: condição corporal, conformação, cobertura de gordura, cor da gordura, cor da carne e consistência da gordura (P>0.05). FERNANDES (1994) observou diferenças significativas para cor da carne e conformação e semelhança para cobertura de gordura, ao avaliar cordeiros Corriedale e Ile-deFrance x Corriedale, terminados em confinamento. Também encontraram diferenças para conformação, entre cordeiros puros e mestiços, LIRETTE et al. (1984), trabalhando com cordeiros de diferentes aptidões, obtiveram resultados diferentes dos encontrados por SAÑUDO et al. (1984), em cordeiros de grupos genéticos de mesma aptidão.

As médias e os desvios-padrão estimados para área de olho de lombo, espessura de gordura e porcentagens de músculo, gordura e osso, no lombo, de acordo com o sistema de terminação e o genótipo, encontram-se na Tabela 2.

Os cordeiros do confinamento apresentaram maior área de olho de lombo $\left(10,21 \mathrm{~cm}^{2}\right)$ que os da pastagem $\left(9,03 \mathrm{~cm}^{2}\right)$, comportamento similar ao verificado por McCLURE et al. (1994). O componente de maior importância na carcaça é o músculo, já que este constitui a carne magra, comestível e disponível para venda. Os músculos de maturidade tardia são indicados para representar o índice mais confiável do desenvolvimento e tamanho do tecido muscular, assim o Longissimus dorsis é o mais indicado, pois, além do

Tabela 2 - Médias e desvios-padrão para área de olho de lombo (AOL), espessura de gordura (EG) e porcentagens de músculo $(M)$, gordura $(G)$ e osso $(O)$ do lombo de cordeiros, conforme o sistema de terminação e o genótipo Table 2 - Means and standard deviations for longissimus muscle area (LMA), fat thickness (FT), lean loin (LL), fat (F) and bone (B) of lambs, according to the finishing system and genotype

\begin{tabular}{|c|c|c|c|c|c|}
\hline \multirow[b]{2}{*}{$\begin{array}{l}\text { Variável } \\
\text { Variable }\end{array}$} & \multicolumn{2}{|c|}{$\begin{array}{l}\text { Sistema de terminação } \\
\text { Finishing system }\end{array}$} & \multicolumn{3}{|c|}{$\begin{array}{l}\text { Genótipo } \\
\text { Genotype }\end{array}$} \\
\hline & $\begin{array}{l}\text { Pastagem } \\
\text { Grazing }\end{array}$ & $\begin{array}{c}\text { Confinamento } \\
\text { Drylot }\end{array}$ & $\mathrm{C}$ & $\mathrm{BC}$ & $\mathrm{HC}$ \\
\hline $\begin{array}{l}\text { AOL } \\
\text { LMA }\end{array}$ & $9,03 \pm 0,25^{b}$ & $10,21 \pm 0,28^{a}$ & $9,70 \pm 0,29^{a}$ & $10,13 \pm 0,26^{\mathrm{a}}$ & $9,05 \pm 0,36^{\mathrm{a}}$ \\
\hline $\begin{array}{l}\mathrm{EG} \\
\mathrm{FT}\end{array}$ & $1,10 \pm 0,15^{\mathrm{b}}$ & $1,70 \pm 0,16^{\mathrm{a}}$ & $1,36 \pm 0,17^{\mathrm{a}}$ & $1,40 \pm 0,15^{\mathrm{a}}$ & $1,44 \pm 0,20^{\mathrm{a}}$ \\
\hline $\begin{array}{l}\mathrm{M} \\
\mathrm{L}\end{array}$ & $54,92 \pm 0,01^{\mathrm{a}}$ & $57,94 \pm 0,01^{\mathrm{a}}$ & $57,40 \pm 0,01^{\mathrm{a}}$ & $54,56 \pm 0,02^{\mathrm{a}}$ & $57,34 \pm 0,01^{\mathrm{a}}$ \\
\hline $\begin{array}{l}\mathrm{G} \\
\mathrm{F}\end{array}$ & $9,29 \pm 0,02^{\mathrm{a}}$ & $12,95 \pm 0,02^{b}$ & $11,81 \pm 0,01^{\mathrm{a}}$ & $10,59 \pm 0,01^{\mathrm{a}}$ & $10,97 \pm 0,01^{\mathrm{a}}$ \\
\hline $\begin{array}{l}\mathrm{O} \\
\mathrm{B}\end{array}$ & $35,78 \pm 0,03^{b}$ & $29,10 \pm 0,03^{\mathrm{a}}$ & $30,78 \pm 0,02^{\mathrm{a}}$ & $34,85 \pm 0,02^{\mathrm{a}}$ & $31,69 \pm 0,01^{\mathrm{a}}$ \\
\hline
\end{tabular}


amadurecimento tardio é de fácil mensuração (SAINZ, 1996). ARNOLD e MEYER (1988) não encontraram diferenças estatísticas, ao compararem cordeiros confinados com os terminados em pastagem irrigada. Provavelmente o não aparecimento de diferenças a favor dos cordeiros confinados possa ser atribuído ao alto valor nutritivo da pastagem irrigada.

Não houve efeito de genótipo sobre a área de olho de lombo. Esperar-se-ia que cordeiros mestiços, sobretudo filhos de pais Hampshire Down, raça de corte, apresentassem valores superiores. Entretanto, deve-se considerar que o grau de sangue se limitou a 50\%. É provável que grupos com maiores proporções de sangue de raça especializada para a produção de carne apresentem-se superiores em relação a esta variável, sobretudo se criados em sistema de confinamento. Resultados semelhantes foram verificados por CROUSE et al. (1981), LLOYD et al. (1981), FERNANDES, (1994) e WYLIE et al. (1997), assim como por WOLF et al. (1980), DAHMEN et al. (1985), ARNOLD e MEYER (1988) e FAHMY et al. (1992), observando efeito de genótipo, para a variável estudada.

A porcentagem de músculo foi semelhante $(\mathrm{P}>0,05)$ para os dois sistemas de terminação, apesar de, em termos absolutos, os cordeiros terminados em confinamento terem apresentado, em média, três pontos percentuais acima dos terminados em pastagem. Considerando que o módulo mínimo econômico, para produção de carne de ovinos, é de 500 matrizes, com produção esperada de 500 cordeiros, para abate, com peso médio de carcaça de $12,92 \mathrm{~kg}$, e $58 \%$ de músculo, para cordeiros terminados em confinamento, e carcaças de $11,45 \mathrm{~kg}$ com $55 \%$ de músculo, em pastagem (MACEDO et al., 1998), é possível obter diferença de 598,00 $\mathrm{kg}$ de músculo a favor dos cordeiros confinados. Os cordeiros do confinamento apresentaram mais gordura $(12,95 \%)$ comparativamente aos da pastagem (média 9,29\%) e menos osso $(29,10 \%$ contra $35,78 \%)(\mathrm{P}<0,05)$. JONES et al. (1984) registraram proporções teciduais semelhantes. Salienta-se que os valores obtidos são compatíveis com carcaças de alta qualidade, ressaltando-se, mesmo no caso dos animais confinados, os excelentes níveis de tecido adiposo.

Não se constatou efeito de genótipo para as porcentagens de músculo, gordura e osso $(\mathrm{P}>0,05)$, estando de acordo com trabalho de GÜNEY (1988), porém diferentes dos resultados verificados por SAÑUDO et al. (1981), LIRETTE et al. (1984), CAMERON e DRURY (1985), FAHMY et al. (1992) e SAÑUDO et al. (1992). Provavelmente o efeito de genótipo encontrado por esses pesquisadores tenha sido decorrente do abate de cordeiros com idade superior à dos cordeiros desse experimento e aos de GÜNEY (1988), permitindo que os mestiços demostrassem sua superioridade.

Médias e desvios-padrão estimados para porcentagem de proteína (P) e lipídio (L), obtida por meio de análise química dos lombos, encontram-se na Tabela 3.

A porcentagem de proteína foi semelhante nos dois sistemas de terminação, concordando com os teores mostrados por MURPHY et al. (1994), que encontraram média de $20,64 \%$, porém inferiores aos $28,5 \%$ mostrado por SEUSS (1990).

Os cordeiros da pastagem apresentaram menor porcentagem de lípideos (média 5,43\%) que os terminados em confinamento $(11,54 \%)(\mathrm{P}<0,05)$; o mesmo comportamento foi detectado por MURPHY et al. (1994), os quais obtiveram 6,59 e $8,62 \%$, respectivamente. O valor médio apresentado por SEUSS (1993),

Tabela 3 - Médias e desvios-padrão para porcentagens de proteína (P) e lipídio (L), do lombo em cordeiros, conforme o sistema de terminação e o genótipo

Table 3 - Means and standard deviations for protein $(P)$ and fat $(F)$ percentage, of the loin of lambs, in function of the finishing system and genotype

\begin{tabular}{|c|c|c|c|c|c|}
\hline \multirow[b]{2}{*}{$\begin{array}{l}\text { Variável } \\
\text { Variable }\end{array}$} & \multicolumn{2}{|c|}{$\begin{array}{c}\text { Sistema de terminação } \\
\text { Finishing system }\end{array}$} & \multicolumn{3}{|c|}{$\begin{array}{l}\text { Genótipo } \\
\text { Genotype }\end{array}$} \\
\hline & $\begin{array}{l}\text { Pastagem } \\
\text { Grazing }\end{array}$ & $\begin{array}{c}\text { Confinamento } \\
\text { Drylot }\end{array}$ & $\mathrm{C}$ & $\mathrm{BC}$ & $\mathrm{HC}$ \\
\hline $\begin{array}{l}\mathrm{P} \\
\mathrm{P}\end{array}$ & $19,71 \pm 0,37^{\mathrm{a}}$ & $19,10 \pm 0,37^{\mathrm{a}}$ & $19,62 \pm 0,40^{a}$ & $19,86 \pm 0,40^{\mathrm{a}}$ & $18,73 \pm 0,37^{a}$ \\
\hline $\begin{array}{l}\mathrm{L} \\
\mathrm{F}\end{array}$ & $5,43 \pm 1,28^{a}$ & $11,54 \pm 1,28^{b}$ & $7,51 \pm 1,39^{a}$ & $7,79 \pm 1,39^{\mathrm{a}}$ & $10,16 \pm 1,28^{a}$ \\
\hline
\end{tabular}

Médias, na linha, seguidas de letras diferentes diferem $(P<0,05$; Tukey).

Means, within a row, followed by different letters differ ( $P<.05 ;$ Tukey).

Corriedale (C); $1 / 2$ Bergamácia + 1/2 Corriedale (BC); $1 / 2$ Hampshire Down + 1/2 Corriedale (HC). 
para carne de cordeiro magra assada, é de 9,5\%. Logo, os valores encontrados podem ser considerados adequados às exigências do mercado.

As porcentagens de proteína e lipídio não sofreram efeito de cruzamentos, opondo-se aos resultados de MEYER e KIRTON (1984), que observaram diferenças nas porcentagens de lipídio, entre cordeiros puros (Romney Marsh: 11,9\% e Perendale: 13,3\%) e mestiços (Merino x Perendale, 15,5\% e Merino x Romney Marsh, 14,8\%), e também de SNOWDER et al. (1994), que encontraram diferenças tanto para proteínas como para lipídios.

\section{Conclusões}

O uso de confinamento para a terminação de cordeiros levou à produção de carcaças com qualidade superior àquelas obtidas com terminação em pastagem.

Cordeiros mestiços de Corriedale produziram carcaças de mesma qualidade que os Corriedale puros.

\section{Referências Bibliográficas}

ARNOLD, A.M., MEYER, H.H. 1988. Effects of gender, time of castration, genotype and feeding regimen on lamb growth and carcass fatness. J. Anim. Sci., 66:2468-2475.

BUTLER-HOGG, B.W. 1984. The growth of Clun and Southdown sheep: body composition and the partitioning of total body fat. Anim. Prod., 39:409-411.

CAMERON, N.D., DRURY, D.J. 1985.Comparison of terminal sire breeds for growth and carcass traits in crossbred lambs. Anim. Prod., 40:315-322.

CAÑEQUE, V., HUIDOBRO, F.R., DOLZ, J.F. 1989. Producción de carne de cordero. Madrid: Ministério de Agricultura Pesca y Alimentación. 520p.

COLOMER-ROCHER, F. Estudio de los parametros que definen los caracteres cuantitativos y cualitativos de las canales. In: CURSO INTERNACIONAL SOBRE PRODUCCIÓN DE CARNE Y LECHE CON BASES EN PASTOS Y FORRAJES. 1988. La Coruña, Espanha. 108p, 1988.

CROUSE, J.D., BUSBOOM, J.R., FERREI, C.L. 1981. The effects of breed, diet, sex, location and slaughter weight on lamb growth, carcass composition and meat flavor. J. Anim. Sci., 53:376-387.

DAHMEN, J.J., JACOBS, J.A., MORRISON, E.J. 1985. Suffolk versus Lincoln rams: the influence of sire and breed cross on carcass traits of heavy market lambs. J. Anim. Sci., 61(1):98-106.

ELliS, M., WEBSTER, G.M., MERRELL, B.G. 1997 The influence of the terminal sire breed on carcass composition and eating quality of crossbred lambs. Anim. Sci., 64:77-86.

FAHMY, M.H., BOUCHER, J.M., POSTE, L.M. et al. 1992. Feed efficiency, carcass characteristics, and sensory quality of lambs, with or without prolific ancestry, fed diets with different protein supplements. J. Anim. Sci., 70:1365-1374.

FARIAS, J.V.S., JARDIM, P.O.C., GUERREIRO, J.L.V. Avaliação de carne de novilhos Hereford. 2.Comparação do peso de carcaça e conformação como estimadores. In: REUNIÃO
ANUAL DA SOCIEDADE BRASILEIRA DE ZOOTECNIA, 23, 1986, Campo Grande. Anais... Campo Grande: SBZ, 1986, p 235.

FERNANDES, S. Peso vivo ao abate e características de carcaça de cordeiros da raça Corriedale e mestiços Ile-de-France $x$ Corriedale, recriados em confinamento. Botucatu, SP: UNESP, 1994. 82p. Dissertação (Mestrado em Zootecnia) Universidade Estadual Paulista, 1994.

FOLCH, J., LEES, M., MORTON, M.L. 1957. A simple method for the isolation and purification of total lipides from animal tissues. J. Biol. Chem., 226:497-509.

GALVÃO, J.G., FONTES, C.A.A., PIRES, C.C. et al. 1991. Caracterização e composição física da carcaça de bovinos não castrados, abatidos em três estágios de maturidade de três grupos raciais. R. Soc. Bras. Zootec., 20:502-512.

GÜNEY, O. A commercial crossbreeding experiment between Ile de France, Rambouillet, Chios and the local fat Awassi for lamb production. Proceedings, World Congress on Sheep and Beef Cattle Breeding, 3, 1988, v.1, n.19-23,. In: ANIM. BREED. ABSTR., 57:29, 1989. (Abstract...).

JARRIGE, R. 1988. Alimentação dos bovinos, ovinos e caprinos. Publicações Europa - América Ltda. 460p.

JONES, S.D.M., BURGESS, T.D., DUPCHAK, K. et al. 1984. The growth performance and carcass composition of ram and ewe lambs fed on pasture or in confinement and slaughtered at similar fatness. Can. J. Anim. Sci., 64: 631-640.

LATIF, M.G.A., OWEN, E. 1980. Comparison of Texel and Suffolk sired lambs out of Finnish Landrace x Dorset Horn ewe under grazing conditions. J. Agric.Sci., 92:235-239.

LIRETTE, A., SEONE, J.R. MINVIELLE, F. et al. 1984. Effects of breed and castration on conformation, classification, tissue distribution, composition and quality of lamb carcass. $J$. Anim. Sci., 58(6):1343-1357.

LLOYD, W.R., SLYTER, A.L., COSTELLO, W.J. 1981. Effect of breed, sex, and final weight on feedlot performance, carcass characteristics and meat palatability of lambs. J. Anim. Sci., 51:316-320.

LOPEZ-FRANCOS, L. 1991. La calidad de la carne de ovino en España. Mundo Ganadero, 4:46-54.

MACEDO, F.AF. Desempenho e características da carcaça de cordeiros Corriedale e mestiços Bergamácia x Corriedale e Hampshire Down x Corriedale, terminados em pastagem e confinamento. Botucatu - SP, UNESP: FMVZ, 1998, 72p. Tese (Doutorado em Zootecnia) - Universidade Estadual Paulista, 1998.

MANTEROLA, B.H., CERDA, A D., SIRHAN, A.L. et al. 1991. Factors affecting carcass conformation and fat in precoce sheep. 1. Effects of body weight at slaughter and nutrition. Anim. Breed. Abst., 59(6):1078-1087.

MEYER, H.H., KIRTON, A.H. 1984. Growth and carcass characteristics of Romney, Perendale, and their Booroola Merino crossbred ram lambs. N. Z. J. Agric. Res., 27:167-172.

McCLURE, K.E., VAN KEUREN, R,W., ALTHOPUSE, P.G. 1994. Performance and carcass characteristics of weaned lambs either grazed on orchardgrass, ryegrass or alfalfa or fed all-concentrate diets in drylot. J. Anim. Sci., 72:3230-3237.

MURPHY, T.A., LOERCH, S.C., McCLURE, K.E. 1994. Effects of grain or pasture finishing systems on carcass composition and tissue accretion rates of lambs. J. Anim. Sci., 72:3138-3144.

OSÓRIO, J.C.S. Estudio de la calidad de canales comercializadas en el tipo ternasco segun la procedencia: bases para la mejora de dicha calidad en Brazil. Zaragoza, 1992. 335p. (Tesis de Doctorado en Veterinaria) - Facultad de Veterinaria, Universidad de Zaragoza, 1992.

OSÓRIO, J.C., MARIA, G.A., PIMENTEL, M. 1995. El Efecto 
del sexo sobre la producción de carne de corderos de raza Corriedale en Brasil. Pelotas, RS: UFRGS. 39p.

SAINZ, R.D. 1996. Produção, qualidade e comercialização de carnes. In: CURSO 1. Ribeirão Preto: Universidade de São Paulo. 14p.

SAÑUDO, C., PIEDRAFITA, J., SIERRA, I. Estudio de la calidad de la canal y de la carne en animales cruzados Romanov por Rasa Aragonesa. 2. Comparación en el tipo comercial ternasco con Rasa en pureza. In: JORNADAS CIENTÍFICAS DE LA SOCIEDAD ESPAÑOLA DE OVINOTECNIA, 7, 1981, Talavera de la Reina. Actas...Zaragoza: 1981. p.483-489.

SAÑUDO, C., SIERRA, I. 1986. Calidad de la canal en la especie ovina. Ovino, 1:127-153.

SAÑUDO, C., SIERRA, I., ALCALDE, M.J. et al. Carcass and meat quality of light and heavy lambs of Rasa Aragonesa, Lacaune and German Merino breeds. In: ANNUAL MEETING OF THE EUROPEAN ASSOCIATION OF ANIMAL PRODUCTION, 1992, Madrid. Proceedings...Madrid, 1992. p.264.

SEUSS, I. 1990. The nutritional value of mead and met products. Fleischwirtsch, 70(12):1444-1444.

SEUSS, I. 1993. The nutritional importance of animal fatty tissue. Fleischwirtsch, 73(7):751-754.
SILVA, D.J. 1990. Análise de alimentos (Métodos químicos e biológicos). 2.ed. Imprensa Universitária/UFV. Viçosa. 165p.

SNOWDER, G.D., GLIMP, H.A., FIELD, R.A. 1994. Carcass characteristics and optimal Slaughter weights in four breeds of sheep. J. Anim. Sci., 72:932-937.

TEIXEIRA, A., DELFA, R., GONCALEZ, C. 1992 El grado de engrasamiento. Rev. Ovis, 19:21-35.

WOLF, B., TSMITH, C., JALES, D.I. 1980. Growth and carcass composition in the crossbred progeny of six terminal sire breeds of sheep. Anim. Prod., 31:307-313.

WYLIE, A.R.G., CHESTNUTT, D.M.B., KILPATRICK, D.J. 1997. Growth and carcass characteristics of heavy slaughter weight lambs: effects of sire breed and sex of lamb and relationships to serum metabolites and IGF-1. Anim. Sci., 64:309-318.

Recebido em: 08/07/98

Aceito em: 22/02/00 